\title{
Genetisch onderzoek bij prostaatkanker: nieuwe ontwikkelingen
}

\author{
Margreet G. E. M. Ausems · Lambertus A. L. M. Kiemeney
}

Published online: 13 February 2020

(C) The Author(s) 2020

\begin{abstract}
Samenvatting Op dit moment wordt kiembaan genetisch onderzoek bij prostaatkanker zelden aangevraagd. Bij mannen met gemetastaseerd prostaatcarcinoom wordt echter relatief vaak een mutatie in een borstkankergen gevonden (met name in BRCA2). In dit artikel worden criteria voor genetisch onderzoek voorgesteld. De uitslag van genetisch onderzoek kan van belang zijn voor familieleden die preventieve maatregelen kunnen nemen om kanker te voorkomen of tijdig op te sporen. De uitslag kan daarnaast ook van belang zijn voor de behandeling van de ziekte. De tijd is rijp om multidisciplinair een werkwijze in te richten waarbij genetisch onderzoek door het behandelteam met de patiënt wordt besproken, de patiënt goed geïnformeerd een keuze kan maken, en de uitslagen in nauwe samenwerking met de klinische genetica worden teruggekoppeld. Voor deze nieuwe werkwijze (mainstreaming van genetisch onderzoek) is adequate scholing nodig van urologen, oncologen en verpleegkundig specialisten.
\end{abstract}

Trefwoorden gemetastaseerd prostaatcarcinoom • kiembaan · BRCA2 - genetisch onderzoek

\section{Genetic testing in patients with prostate cancer: new developments}

Abstract At this moment, germline genetic testing is rarely requested in patients with prostate cancer.

\footnotetext{
dr. M. G. E. M. Ausems ( $\varangle)$

Afdeling Genetica, Divisie Laboratoria, Apotheek en Biomedische Genetica, Universitair Medisch Centrum Utrecht, Utrecht, Nederland m.g.e.m.ausems@umcutrecht.nl

prof. dr. L. A. L. M. Kiemeney

Afdeling Health Evidence en afdeling Urologie,

Radboudumc Nijmegen, Nijmegen, Nederland
}

However, a breast cancer gene mutation is frequently detected in men with metastasized prostate cancer (mainly in BRCA2). In this paper we propose criteria for genetic testing in prostate cancer. Genetic test results may have major implications for relatives who may take appropriate measures to prevent cancer or diagnose it at an early stage. It may also have direct relevance for the treatment of the patient. It is time to set up a new workflow enabling treating physicians to order a DNA test (mainstreaming of genetic testing). It calls for close collaboration between clinical geneticists and treating physicians, and adequate education of urologists, oncologists and specialized nurses.

Keywords metastatic prostate cancer - germline BRCA2 - mainstreaming genetic testing

\section{Introductie}

De etiologie van prostaatkanker is multifactorieel. Uit onderzoek blijkt dat de incidentie van prostaatkanker varieert in verschillende landen, en ook binnen populaties met een verschillende etnische achtergrond [1]. Dit suggereert dat zowel genetische als omgevings- en leefstijlfactoren een rol spelen [2]. De belangrijkste risicofactoren voor prostaatkanker zijn leeftijd, familieanamnese en etniciteit.

Op basis van internationaal gebruikte criteria is sprake van 'erfelijke' aanleg voor prostaatkanker (HPC) bij: 1) drie of meer familieleden met prostaatkanker van wie één persoon een eerstegraads familielid is van de andere twee; 2) twee of meer eerstegraads familieleden met prostaatkanker met een diagnoseleeftijd < 55 jaar; 3) prostaatcarcinoom in drie opeenvolgende generaties binnen één tak van de familie [3, 4]. In deze criteria is echter het fenotype van de prostaatkanker niet meegenomen. Het is zinvol om, naast het aantal aangedane familiele- 
den, de aard van de prostaatkanker mee te nemen en laagrisicotumoren te negeren. Een voorstel zou kunnen zijn om prostaatkanker met tumorstadium $\leq \mathrm{cT} 2 \mathrm{~b}$ en Gleason-score $\leq 6$ of PSA $<10$ niet mee te nemen bij de inschatting of er sprake is van HPC. De kans is namelijk redelijk groot dat deze tumoren diagnostiekgerelateerd zijn in plaats van erfelijk [5].

Bij een zeer klein deel van de families die voldoen aan de criteria voor HPC kan een kiembaanmutatie met een hoog risico op prostaatkanker worden aangetoond. Veel vaker gaat het in deze families om een combinatie van verschillende genetische varianten (single-nucleotide polymorphisms; SNP's) die elk een licht verhoogd risico op prostaatkanker geven. Inmiddels zijn er vele SNP's ontdekt die samenhangen met prostaatkanker. In een recent review van Genome-Wide Association Studies blijkt dat zo'n 170 SNP's ruim $28 \%$ verklaren van het familiaire relatieve risico op prostaatkanker, en dat zo'n $6 \%$ verklaard wordt door zeldzame genetische varianten met een relatief hoog risico (zoals mutaties in het BRCA2- of het HOXB13-gen) [2].

In dit artikel wordt een overzicht gegeven van recente studies met betrekking tot hoogrisico-kiembaanmutaties bij mannen met prostaatkanker, en wordt een voorstel gedaan voor de praktijk om genetisch onderzoek routinematig aan te bieden aan een geselecteerde groep patiënten met prostaatkanker.

\section{DNA-onderzoek bij mannen met gemetastaseerde prostaatkanker}

In 2016 werden de resultaten gepubliceerd van een grote studie naar kiembaanmutaties bij patiënten met gemetastaseerde ziekte die niet waren geselecteerd voor leeftijd of familieanamnese [6]. Eerder had deze onderzoeksgroep genetisch onderzoek verricht aan metastasen van 150 patiënten met castratieresistente prostaatkanker om aanknopingspunten te vinden voor therapie [7]. Voor vergelijkend onderzoek was toen ook DNA-onderzoek van de kiembaan verricht. Tot verbazing van de onderzoekers werd bij $8 \%$ van de patiënten een mutatie in een DNA-repairgen gevonden. Deze bevinding suggereerde dat mannen met gemetastaseerde ziekte een subgroep vormen waarin vaker een kiembaanmutatie in een DNA-repairgen voorkomt. DNA-repairgenen zijn betrokken bij herstel van DNA-schade. Om dit te bevestigen, is bij 692 mannen met bewezen gemetastaseerde ziekte onderzoek verricht van 20 DNA-repairgenen, zoals BRCA1, BRCA2 en de mismatch-repairgenen [6]. Bij 11,8\% van de patiënten werd een kiembaanmutatie aangetoond, waarvan de meest voorkomende in BRCA2 (37 mutaties; $44 \%$ van het totaal aantal mutaties), ATM (11; 13\%), CHEK2 (10; 12\%), BRCA1 (6; 7\%), RAD51D (3; $4 \%)$ en $P A L B 2(3 ; 4 \%)$. Er was geen associatie met leeftijd of familieanamnese. De mutatieprevalentie was significant hoger dan die in een groep van 499 patiënten met gelokaliseerd prostaatcarcinoom $(4,6 \%)$, en in een groep van 53.105 personen zonder kanker $(2,7 \%)$. Dit suggereert dat het relevant kan zijn om DNA-onderzoek van DNA-repairgenen routinematig aan te bieden aan alle mannen met gemetastaseerde prostaatkanker.

Na deze studie van Pritchard et al. zijn meerdere studies gepubliceerd met resultaten van onderzoek naar kiembaanmutaties bij patiënten met gemetastaseerde prostaatkanker (tab. 1 ; [8-11]). In deze studies is bij grote groepen patiënten een wisselend aantal genen onderzocht, variërend van alleen het BRCA1en BRCA2-gen [10] tot 28 [9], 30 [11] of 76 verschillende kankerpredispositiegenen [8]. De mutatiedetectie varieert van 3,1\% [10] (alleen onderzoek BRCA1en BRCA2-gen) tot $19 \%$ [8] indien ook andere kankerpredispositiegenen worden onderzocht. Verreweg de meeste mutaties worden gevonden in het BRCA2gen, gevolgd door het ATM-gen en het CHEK2-gen. Er lijkt geen relatie te zijn met de familieanamnese (voor prostaatkanker, of andere vormen van kanker) of leeftijd [11]. Bij toepassing van de Amerikaanse criteria voor genetisch onderzoek bij borst- en eierstokkanker (te weten: hoogrisico-prostaatkanker Gleason-score $\geq$ 7 met één familielid met ovarium- of mammacarcinoom $<50$ jaar, of twee familieleden met borst-, pancreas- of prostaatkanker Gleason-score $\geq 7$ ) [12] blijkt dat $44 \%$ van de opgespoorde mutatiedragers geen indicatie had voor een DNA-test [11]. Dit geeft aan dat andere klinische criteria moeten worden opgesteld om mannen met prostaatkanker te identificeren die in aanmerking komen voor genetisch onderzoek.

Een evaluatie van de huidige (Amerikaanse) verwijscriteria is in 2019 gepubliceerd door Nicolosi et al. [13]. In deze studie is in een groot cohort van prostaatkankerpatiënten $(n=3.607)$ kiembaanonderzoek verricht van een wisselend aantal kankerpredispositiegenen. Het gebruikte genpanel bestond bij $62 \%$ van de patiënten uit 14 genen (ATM, BRCA1, BRCA2, CHEK2, EPCAM, HOXB13, MLH1, MSH2, MSH6, NBN, PMS2, TP53, $R A D 51 D$, en $P A L B 2)$. De patiënten waren ongeselecteerd voor familieanamnese, diagnoseleeftijd, tumorstadium of Gleason-score. Bij 17,2\% werd een kiembaanmutatie aangetoond; $24,3 \%$ van de gevonden mutaties betrof een BRCA2-mutatie, gevolgd door CHEK2 (14,1\%) en ATM (9,6\%). Ruim 1/3 (37\%) van de geïdentificeerde mutatiedragers had geen indicatie voor genetisch onderzoek op basis van de huidige NCCN-verwijscriteria voor borst- en eierstokkanker (te weten: hoogrisico-prostaatkanker Gleason-score $\geq$ 7 met één familielid met ovarium-, mammacarcinoom $<50$ jaar, of twee familieleden met borst- pancreas- of prostaatkanker Gleason-score $\geq 7$ of gemetastaseerde prostaatkanker). Op grond hiervan wordt door Nicolosi et al. gesuggereerd om genetisch onderzoek bij elke man met prostaatkanker te overwegen. Echter, van een relatief groot deel van de onderzoekspopulatie waren de klinische gegevens niet compleet (Gleason-score of ziektestadium ontbraken). Een dergelijke 
Tabel 1 Overzicht van de literatuur

\begin{tabular}{|c|c|c|c|c|c|}
\hline Studie & Land & Npat & $\begin{array}{l}N \\
\text { genen }\end{array}$ & Ziektestadium & $N(\%)$ kiembaanmutatie $^{\mathrm{a}}$ \\
\hline $\begin{array}{l}\text { Pritchard et al. } \\
\text { (2016) [6] }\end{array}$ & $V S+U K$ & 692 & 20 & $\mathrm{mPC}$ & $\begin{array}{l}82(11,8 \%) \\
B R C A 2, A T M \text { en CHEK2 }\end{array}$ \\
\hline $\begin{array}{l}\text { Velho et al. (2018) } \\
\text { [11] }\end{array}$ & VS & 150 & 30 & $\mathrm{mPC}$ of recidief & $\begin{array}{l}21(14 \%) \\
\text { BRCA2, ATM en CHEK2 }\end{array}$ \\
\hline $\begin{array}{l}\text { Abida et al. (2017) } \\
\text { [8] }\end{array}$ & VS & 451 & 76 & mPC: 348 (77\%), locoregionaal of biochemisch recidief: 103 & $\begin{array}{l}42(19 \%) \\
B R C A 2, \text { CHEK2, ATM }\end{array}$ \\
\hline Giri et al. (2017) [9] & VS & 200 & 28 & PC (125) & $\begin{array}{l}11(5,5 \%) \\
\text { MUTYH, ATM, BRCA1/ } \\
\text { BRCA2/BRIP1 }\end{array}$ \\
\hline $\begin{array}{l}\text { Petrovics et al. } \\
(2018)[10]\end{array}$ & VS & 1240 & $\begin{array}{l}2 \\
\text { (BRCA1, } \\
\text { BRCA2) }\end{array}$ & $\begin{array}{l}\text { Gelokaliseerd in vroeg stadium (T2) } \\
\text { PC: } 935 \text { (75\%); uitgebreid PC (50\% T3-4): } 189 \text { (15\%) en } \\
\text { mPC: } 116(10 \%)\end{array}$ & $\begin{array}{l}(0,7 \%) \text { bij gelokaliseerd PC } \\
(3,1 \%) \text { bij mPC }\end{array}$ \\
\hline $\begin{array}{l}\text { Nicolosi et al. (2019) } \\
\text { [13] }\end{array}$ & VS & 3607 & 14 & $\begin{array}{l}\text { mPC: } 542(15 \%) \\
\text { Gleason-score } \geq 7: 1391\end{array}$ & $\begin{array}{l}620(17,2 \%) \\
\text { BRCA2, CHEK2, ATM }\end{array}$ \\
\hline \multicolumn{6}{|c|}{$\begin{array}{l}N \text { pat. aantal patiënten dat in de studie werd geïncludeerd, } N g \\
P C \text { prostaatcarcinoom } \\
\text { a De drie meest voorkomende genen } \\
{ }^{b} B R C A 1 / B R C A 2 / B R I P 1 \text { met alle eenmaal een kiembaanmutatie }\end{array}$} \\
\hline
\end{tabular}

aanbeveling kunnen wij op dit moment daarom nog niet ondersteunen.

In het genpanel dat Nicolosi et al. gebruikten, is ook het HOXB13-gen opgenomen [13]. Sinds 2012 is bekend dat een specifieke mutatie in dit gen (G84E, rs138213197) vaker voorkomt bij mannen met prostaatkanker, in vergelijking met een controlepopulatie, en dat de mutatie vooral wordt aangetoond bij mannen met een diagnoseleeftijd < 55 jaar, of een positieve familieanamnese voor prostaatkanker. De HOXB13-mutatie is in Europa een zeldzame risicofactor voor prostaatkanker; in Nederland werd de mutatie bij $1,5 \%$ van de ruim 1.500 onderzochte patiënten met prostaatkanker aangetoond, en bij $0,2 \%$ van de controlepopulatie [14]. In de studies naar kiembaanmutaties bij patiënten met gemetastaseerde prostaatkanker (tab.1) is het HOXB13-gen niet opgenomen in de gebruikte genpanels, met uitzondering van het onderzoek van Nicolosi et al. [13]. In hun onderzoek werd bij 30 van de $3.607(0,8 \%)$ patiënten een HOXB13-mutatie aangetoond, waarvan 24 bij patiënten met een Kaukasische achtergrond. Het is niet bekend of de patiënten met een HOXB13-mutatie een positieve familieanamnese voor prostaatkanker hadden.

Een aangetoonde kiembaanmutatie bij een patient met prostaatkanker kan van invloed zijn op de behandeling van de ziekte $[15,16]$, maar is uiteraard ook voor familieleden van de patiënt relevant. Met de juiste maatregelen kan kanker bij een familielid vroegtijdig worden opgespoord (bijvoorbeeld PSA-screening bij dragers van een BRCA2-mutatie), of worden voorkomen (bijvoorbeeld preventieve verwijdering van adnexen bij vrouwen met een BRCA1mutatie). Een beperking van de studie van Nicolosi et al. en de andere studies naar kiembaanmutaties is dat verreweg de meeste patiënten een Kaukasische (blanke) achtergrond hebben, en dat patiënten met bijvoorbeeld een Afrikaanse, Spaanse, Aziatische of joodse achtergrond ondervertegenwoordigd zijn in de onderzoekspopulatie. Het is op dit moment niet bekend of de mutatiepercentages net zo hoog zijn voor patiënten met een niet-Kaukasische achtergrond.

\section{Criteria voor genetisch onderzoek bij prostaatkanker}

In de Nederlandse 'Richtlijn prostaatcarcinoom' staat dat bij iedere patiënt de familieanamnese dient te worden afgenomen [17]. Als er op basis van de familieanamnese aanwijzingen zijn voor erfelijk prostaatcarcinoom, wordt periodiek onderzoek verricht volgens de adviezen van de Stichting Opsporing Erfelijke Tumoren (StOET) $[3,18]$. In deze adviezen wordt uitgegaan van het voorkomen van prostaatcarcinoom in de familie, en niet van andere vormen van kanker. Criteria voor verwijzing naar de klinische genetica of criteria voor verwijzing voor genetisch onderzoek zijn nog niet opgenomen in de 'Richtlijn prostaatcarcinoom'. Inmiddels weten we dat het zinvol is om bij een patiënt ook naar andere vormen van kanker te informeren. In de Nederlandse 'Richtlijn borstkanker' [19] is het voorkomen van borstkanker op een leeftijd $<50$ jaar en prostaatkanker op een leeftijd $<60$ jaar bij een eerstegraads verwant aan dezelfde kant van de familie een indicatie voor verwijzing naar de klinische genetica, omdat de kans op een BRCA1- of BRCA2genmutatie in dat geval verhoogd is.

In de 'NCCN-richtlijn prostaatcarcinoom' [20] wordt geadviseerd om bij elke patiënt een uitgebreide familieanamnese af te nemen, en na te gaan of er behalve prostaatkanker ook aan BRCA-gerelateerde of aan het Lynch-syndroom gerelateerde tumoren voorkomen (borst- eierstokkanker, pancreas-, colon-, endometrium-, maag-, nier-, galweg-, dunnedarm-, of urotheelcelkanker). Drie of meer van deze vor- 
Tabel 2 Criteria voor genetisch onderzoek bij prostaatkanker

\author{
1. Prostaatkanker, gemetastaseerd, ongeacht familie-anamnese \\ 2. Twee of meer familieleden met prostaatkanker ${ }^{a}$ met Gleason-score $\geq 7$ en $<55$ jaar \\ 3. Prostaatkanker met Gleason-score $\geq 7$ en familielid met mammacarcinoom $<50$ jaar $^{\text {a }}$ \\ 4. Prostaatkanker met Gleason-score $\geq 7$ en eierstokkanker ${ }^{a}$ \\ 5. Prostaatkanker met Gleason-score $\geq 7$ en alvleesklierkanker ${ }^{a}$ \\ 6. Prostaatkanker met Gleason-score $\geq 7$ en joodse afkomst \\ a eerste- of tweedegraads familielid
}

men van kanker aan dezelfde kant van de familie, zijn een indicatie voor genetisch onderzoek, vooral bij een diagnoseleeftijd < 50 jaar. Ook bij een joodse achtergrond kan DNA-onderzoek van de BRCA-genen overwogen worden, omdat patiënten met Asjkenazisch-joodse voorouders namelijk een grotere kans hebben om drager van een BRCA1- of BRCA2-mutatie te zijn [21]. Wanneer er geen positieve familieanamnese is, maar wel een hoogrisico gelokaliseerd prostaatcarcinoom wordt in de NCCN-richtlijn genetisch onderzoek aanbevolen, evenals wanneer er sprake is van gemetastaseerde ziekte [20]. Geadviseerd wordt om dan de borstkankergenen BRCA1, BRCA2, CHEK2, $A T M$ en $P A L B 2$ te onderzoeken, evenals de genen voor het Lynch-syndroom MLH1, MSH2, MSH6 en PMS2. Het is op dit moment nog de vraag of dit advies ook voor de Nederlandse situatie van toepassing is. In de Europese en Nederlandse richtlijn [1, 17] is nog geen aanbeveling voor genetisch onderzoek opgenomen. Ons advies is om bij elke patiënt met prostaatkanker een uitgebreide familieanamnese af te nemen, en na te gaan of er aan BRCA of aan het Lynch-syndroom gerelateerde tumoren in de familie voorkomen. Indien er aanwijzingen zijn voor het Lynch-syndroom in de familie [22], is verwijzing naar de klinische genetica zinvol, zodat onderzoek van de mismatch repairgenen bij de patiënt of een familielid kan worden ingezet wanneer hiervoor inderdaad een indicatie bestaat. Wanneer er geen aanwijzingen zijn voor het Lynch-syndroom, stellen wij voor om voorlopig andere criteria voor genetisch onderzoek te gebruiken (tab.2). Bij patiënten die voldoen aan een van de criteria in tab. 2 kan onderzoek van de borstkankergenen (BRCA1, BRCA2, CHEK2, PALB2 en ATM) worden verricht. Alleen bij patiënten met een positieve familieanamnese voor prostaatkanker (criterium 2 uit tab. 2) kan daarnaast ook onderzoek van het HOXB13gen overwogen worden. Verder onderzoek en nadere afstemming zijn echter nodig. We doen hierbij een oproep aan de EAU-Richtlijncommissie om dit op te pakken.

\section{Mainstreaming van genetisch onderzoek van de kiembaan}

Uitslagen van genetisch onderzoek van de kiembaan zijn in toenemende mate belangrijk voor de behandeling van kanker, en ook voor deelname aan klinische trials [16]. Voor andere vormen van kanker vragen behandelaars steeds vaker zelf een DNA-test aan in plaats van de patiënt voor een DNA-test te verwijzen naar de klinische genetica, zodat genetisch onderzoek laagdrempelig beschikbaar is, aan meer patienten wordt aangeboden en uitslagen sneller bekend zijn [22]. Dit wordt mainstreaming van genetisch onderzoek genoemd. In Engeland is veel ervaring opgedaan met deze werkwijze bij patiënten met ovariumcarcinoom [23]. Alleen patiënten met een mutatie of positieve familieanamnese worden verwezen naar de klinische genetica. Dit is minder belastend voor patiënten, goedkoper en er wordt efficiënter gebruikgemaakt van de expertise en capaciteit van klinisch genetici. Ook in Nederland zijn verschillende projecten gestart voor patiënten met ovarium- en mammacarcinoom.

Het is te verwachten dat de vraag naar kiembaandiagnostiek voor patiënten met prostaatcarcinoom fors zal toenemen. Een recente survey onder oncologen in 19 Amerikaanse prostaatkankerbehandelcentra laat zien dat de meerderheid (62\%) van hen kiembaanonderzoek overweegt bij alle patiënten met gemetastaseerd prostaatcarcinoom [24]. Belangrijke barrières hierbij zijn: beperkte toegang tot erfelijkheidsonderzoek, geen dekking van de kosten van genetisch onderzoek, het ontbreken van een efficiënte workflow en geschikt voorlichtingsmateriaal, en daarnaast zelf te weinig tijd hebben om het genetisch onderzoek te bespreken. Urologen, oncologen en radiotherapeuten hebben baat bij nieuw te ontwikkelen trainingen en voorlichtingsmateriaal [24]. De vraag is of urologen en oncologen zelf genetisch onderzoek kunnen bespreken en aanvragen [25]. Er zijn verschillende werkwijzen mogelijk: 1) de patiënt wordt voor genetisch onderzoek verwezen naar de klinische genetica, 2) de uroloog of oncoloog doet de pretest counseling, vraagt het onderzoek aan, en bespreekt de uitslag of 3) de uroloog of oncoloog doet de pretest counseling en vraagt het onderzoek aan, en de klinisch geneticus bespreekt de uitslag [25]. Naar ons idee is er nog een vierde model mogelijk, gebaseerd op de in Engeland ontwikkelde mainstreamingprocedure: de uroloog of oncoloog doet de pretest counseling, vraagt het onderzoek aan, de klinische genetica informeert patiënt en aanvragend arts schriftelijk over de uitslag en de klinisch geneticus bespreekt de uitslag op de polikliniek met de patiënt wanneer er een mutatie is aangetoond. Het is een uitdaging om samen met de verschillende beroepsgroepen, verpleegkundig specialisten en pati- 
entenorganisaties in Nederland een goede werkwijze in te richten, zodat zo veel mogelijk patiënten met prostaatkanker én een indicatie voor genetisch onderzoek van de kiembaan, een DNA-test krijgen aangeboden, om vervolgens goed geïnformeerd een keuze te kunnen maken. Training van de zorgverleners is een belangrijk onderdeel, evenals korte lijnen tussen de klinisch genetici en de behandelend medisch specialisten [22]. Recentelijk is ons projectvoorstel Routine germline testing of breast cancer genes in men with metastatic prostate cancer to identify relatives at increased cancer risk goedgekeurd door KWF Kankerbestrijding. Dit betekent dat in 2020 in een groot aantal ziekenhuizen in Nederland een start wordt gemaakt met een nieuwe werkwijze, waarbij urologen en oncologen getraind worden om zelf een DNA-test te bespreken en aan te vragen bij een geselecteerde groep patiënten met prostaatkanker (mannen met gemetastaseerde ziekte). De patiëntenorganisaties ProstaatKankerStichting (PKS) en Borstkankervereniging Nederland (BVN)/Oncogen zijn betrokken geweest bij de opzet van dit voorstel, en zullen ook bij de verdere uitvoering ervan een bijdrage blijven leveren.

\section{Beschouwing/Conclusie}

De indicaties voor genetisch onderzoek bij prostaatcarcinoom zijn in beweging. Een groeiend aantal patienten met prostaatcarcinoom heeft een indicatie voor genetisch onderzoek van de kiembaan, omdat de uitslag van dit onderzoek van belang is voor persoonsgerichte therapie. Een aangetoonde mutatie in een kankerpredispositiegen heeft ook consequenties voor familieleden, die drager kunnen zijn. De tijd is rijp om multidisciplinair een werkwijze in te richten waarbij genetisch onderzoek door het behandelteam met de patiënt wordt besproken, de patiënt goed geïnformeerd een keuze kan maken, en de uitslagen in nauwe samenwerking met de klinische genetica worden teruggekoppeld. Voor deze nieuwe werkwijze (mainstreaming) is adequate scholing van urologen, oncologen en verpleegkundig specialisten nodig.

Open Access This article is distributed under the terms of the Creative Commons Attribution 4.0 International License (http://creativecommons.org/licenses/by/4.0/), which permits unrestricted use, distribution, and reproduction in any medium, provided you give appropriate credit to the original author(s) and the source, provide a link to the Creative Commons license, and indicate if changes were made.

\section{Literatuur}

1. Mottet N, Bergh R van den, Briers E, Bourke L, Cornford P, Santis S de, et al. EAU-STRO-ESUIR-SIOG Guidelines on Prostate Cancer. Arnhem: EAU: 2018. http://uroweb. org/guidelines/compilations- of-all-guidelines/. Geraadpleegd op: 7 jan 2020.

2. Benafif S, Kote-Jarai Z, Eeles RA, Consortium P. A review of prostate cancer Genome-Wide Association
Studies (GWAS). Cancer Epidemiol Biomarkers Prev. 2018;27:845-57.

3. Vasen HFA, Hes FJ, Jong MM de. Erfelijke tumoren: richtlijnen voor diagnostiek en preventie 2017. 6e druk. Leiden: Stichting Opsporing Erfelijke Tumoren (STOET) / Vereniging KlinischeGenetica Nederland (VKGN);2017.

4. Carter BS, Bova GS, Beaty TH, Steinberg GD, Childs B, Isaacs WB, et al. Hereditary prostate cancer: epidemiologic and clinical features. J Urol. 1993;150:797-802.

5. Cremers RG, Aben KK, Oort IM van, Sedelaar JP, Vasen HF, Vermeulen SH, et al. The clinical phenotype of hereditary versus sporadic prostate cancer: HPC definition revisited. Prostate. 2016;76:897-904.

6. Pritchard CC, Mateo J, Walsh MF, De Sarkar N, Abida W, Beltran $\mathrm{H}$, et al. Inherited DNA-repair gene mutations in men with metastatic prostate cancer. $\mathrm{N}$ Engl J Med. 2016;375:443-53.

7. Robinson D, Allen EM van, Wu YM, Schultz N, Lonigro RJ, Mosquera JM, et al. Integrative clinical genomics of advanced prostate cancer. Cell. 2015;162:454.

8. Abida W, Armenia J, Gopalan A, Brennan R, Walsh M, Barron D, et al. Prospective genomic profiling of prostate cancer across disease states reveals germline and somatic alterations that may affect clinical decision making. JCO Precis Oncol. 2017; https://doi.org/10.1200/PO.17.00029.

9. Giri VN, Obeid E, Gross L, Bealin L, Hyatt C, Hegarty SE et al. Inherited mutations in men undergoing multigene panel testing for prostate cancer: emerging implications for personalized prostate cancer genetic evaluation. JCO Precis Oncol. 2017; https://doi.org/10.1200/PO.16.00039.

10. Petrovics G, Price DK, Lou H, Chen Y, Garland L, Bass S, et al. Increased frequency of germline BRCA2 mutations associates with prostate cancer metastasis in a racially diverse patient population. Prostate Cancer Prostatic Dis. 2019;22:406-10.

11. Isaacsson Velho P, Silberstein JL, Markowski MC, Luo J, Lotan TL, Isaacs WB, et al. Intraductal/ductal histology and lymphovascular invasion are associated with germline DNA-repair gene mutations in prostate cancer. Prostate. 2018;78(5):401-7.

12. Network NCC. NCCN clinical practice guidelines in oncology: genetic/familial high risk assessment: breast and ovarian. Plymouth Meeting: NCCN. 2017.

13. Nicolosi P, Ledet E, Yang S, Michalski S, Freschi B, O'Leary E, etal. Prevalence of germline variants in prostate cancer and implications for current genetic testing guidelines. JAMA Oncol. 2019;5:523-8.

14. Gudmundsson J, Sulem P, Gudbjartsson DF, Masson G, Agnarsson BA, Benediktsdottir KR, et al. A study based on whole-genome sequencing yields a rare variant at $8 \mathrm{q} 24$ associated with prostate cancer. Nat Genet. 2012;44:1326-9.

15. Smits M, Gerritsen W, Mehra N. Future therapeutic strategies for metastatic prostate cancer. Tijdschr Urol. 2019;6/7:117-30.

16. Mehra N. Behandeling van prostaatkanker bij mannen met een somatische of kiembaan BRCA-mutatie. Tijdschr Urol. 2020;1. https://doi.org/10.1007/s13629-020-00285-9.

17. Integraal Kankercentrum Nederland. Richtlijn Prostaatkanker. Utrecht: IKNL. 2016. https://www.oncoline.nl/ prostaatcarcinoom. Geraadpleegd op: 7 jan 2020.

18. Cremers R. Wat als prostaatkanker in de familie voorkomt? Tijdschr Urol. 2020;1. https://doi.org/10.1007/s13629020-00283-x.

19. Integraal Kankercentrum Nederland. Richtlijn Borstkanker. Utrecht: IKNL. 2017. http:/ /www.oncoline.nl/erfelijken-familiair-ovariumcarcinoom. Geraadpleegd op: 7 jan 2020. 
20. National Comprehensive Cancer Network. NCCN Clinical Practice Guidelines in Oncology (NCCN Guidelines). Plymouth Meeting: NCCN. 2019. https://www.nccn.org/ professionals/physician_gls/pdf/prostate.pdf. Geraadpleegd op: 7 jan 2020.

21. MenkoFH, RosenbergEH, KolkLEvan der. BRCAmutations more frequent in people of Jewish ancestry. Ned Tijdschr Geneeskd. 2019;163:D3663.

22. Ausems M, Oosterwijk JC, Nielsen M, Lolkema MP, Hoogerbrugge N, Ligtenberg MJL. Genetic testing in patients with cancer; new developments. Ned Tijdschr Geneeskd. 2019;20:163.

23. George A, Riddell D, Seal S, Talukdar S, Mahamdallie S, Ruark E, et al. Implementing rapid, robust, cost-effective, patient-centred, routine genetic testing in ovarian cancer patients. SciRep. 2016;6:29506.
24. Paller CJ, Antonarakis ES, Beer TM, Borno HT, Carlo MI, George DJ, et al. Germline genetic testing in advanced prostate cancer; practices and barriers: survey results from the Germline Genetics Working Group of the Prostate Cancer Clinical Trials Consortium. Clin Genitourin Cancer. 2019;17(4):275-282.e1.

25. Giri VN, Hyatt C, Gomella LG. Germline testing for men with prostate cancer: navigating an expanding new world of genetic evaluation for precision therapy and precision management. JClin Oncol. 2019;37:1455-9.

dr. Margreet G.E.M. Ausems, klinisch geneticus

prof. dr. Lambertus A.L.M. Kiemeney, hoogleraar Epidemiologie 